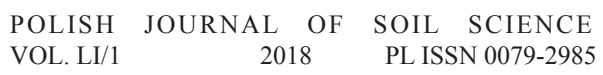

DOI: $10.17951 / \mathrm{pjss} / 2018.51 .1 .41$

MAALIOU AZIZ, MOUZAI LIATIM*

\title{
THE RELATIONS BETWEEN THE RAINFALL EROSIVITY INDEX AI AND THE HYDRAULICS OF OVERLAND FLOW AND SEDIMENT CONCENTRATION IN SANDY SOILS
}

Abstract. The purpose of this study is to investigate the effects of rainfall erosivity index AI on the hydraulics of overland flow parameters such as, the flow velocity, the flow depth, the flow regime, overland flow power and on soil surface characteristics, such as surface roughness and sediment concentration. The erosivity index AI represents six rainfall intensities, $31.40 \mathrm{~mm} \cdot \mathrm{h}^{-1}$; $37.82 \mathrm{~mm} \cdot \mathrm{h}^{-1} ; 69.49 \mathrm{~mm} \cdot \mathrm{h}^{-1} ; 81.85 \mathrm{~mm} \cdot \mathrm{h}^{-1} ; 90.39 \mathrm{~mm} \cdot \mathrm{h}^{-1}$ and $101.94 \mathrm{~mm} \cdot \mathrm{h}^{-1}$ generated by a rainfall simulator. To simulate the soil plot, a soil tray was filled with remolded agricultural sandy soil. The results found have shown that the AI represents better the rainfall than rainfall intensity and related to drop diameter with a power function. Overland flow never exceeded the laminar and subcritical regime; the Reynolds number reacted differently with AI and rainfall intensity, whereas the Froude number has similar reaction with both parameters. Re, Fr and n follow with AI logarithmic, linear and power functions respectively. Finally, AI is a good predictor of soil erosion.

Keywords: rainfall simulator, soil tray, erosivity index AI, overland flow regime, sediment concentrations

* LEGHYD Laboratory, Faculty of Civil Engineering, University of Sciences and Technology Houari Boumediene, PB 32, Bab Ezzouar, Algiers, Algeria; corresponding author: amaaliou@usthb.dz 


\section{INTRODUCTION}

Among the purposes of soil erosion research is to determine the erosive effects of rainfall, especially the effects of raindrops impact. In the literature, the latter phenomenon generally referred to the term rainfall erosivity or potential ability of rainfall to erode soil. In the recent research, the erosivity of natural rainfall developed to determine the artificial rainfall erosivity index. This serves as an important parameter for the calculation of potential soil erosion, if soil erodibility and the other soil surface parameters are known as well. Several methods were developed and used to study the erosive rainfall effects on soil erosion (Meyer 1958, Lal 1977, Kinnell 1981, Zhao et al. 2015). These methods are based on the combination of rainfall characteristics parameters. The effect of rainfall was treated under a single drop parameters such as, velocity diameter, kinetic energy, drop force, drop pressure, drop power; and under rainfall parameters such as, rainfall depth, intensities, duration, the total amount of rain, the area of impact and all the soil characteristics were investigated to enhance the understanding of soil erosion (Marshall and Palmer 1948, Palmer 1965, Kinnell 1981, Mualem and Assouline 1986, El Kateb et al. 2013, Guo et al. 2013a).

The first measurement of the sizes of raindrops was made in 1892 by Lowe (Zachar 1982), who measured the size of the stain made by a raindrop on a slate. By further investigation, the size of raindrops, drop disintegration, and other processes governed by meteorological conditions are known. More research is investigated on this subject, and more results are reported. Detailed studies carried out by Laws (1941) concern the velocity of raindrops. Laws and Parsons (1943) studied the structure of raindrops in rainfall of different intensities, and Hudson (1995) reported the average size of raindrops and other properties. According to the reviewed literature, we point out that many papers have treated the subject of drop characteristics leading to the determination of the rainfall erosive effects. An important step forward in understanding the relationships between the kinetic energy of rain and its erosive effect on soil erosion was made by Ellison (1944), who carried out the first investigation of the process of raindrop erosion, particularly with regard to the disaggregation of soil raindrops splash.

In order to overcome the disadvantages of stationary volumetric methods involving long observation periods and expensive installations, a new approach has used the technique of sprinkling water on experimental plots, measuring the amount and intensity of the artificial rain, the energy of the falling drops, the discharge of surface runoff, and the flow of the mixture. Such methods are called rainfall simulation methods.

The rainfall erosivity factor is defined as a combination of two factors, the rainfall energy (the erosive force) and the maximum continuous 30-min intensity (Wischmeier, 1959). The quantitative expression of energy per unit of rainfall 
that, Wischmeier and Smith (1978) developed, was based on the work of Laws and Parsons (1943). This rainfall energy is known as erosivity index $\left(\mathrm{EI}_{30}\right)$. It is then a function of total rainfall, rainfall distribution, rainfall intensity, rain frequency and rainfall terminal velocity. Soil particles are detached from the soil surface by the raindrops impact and shearing force of flowing water. The erosivity of rainfall can be split into two components. The first component is the kinetic energy contained in a drop when hitting the soil (action of rainfall). The impact of raindrops detaches and displaces particles from the soil matrix, which are then added to particles detached by overland flow (action of runoff). The second component is the erosive power of overland flow. It is equal to the energy of water supplied by slope gradient. Many authors have investigated the climatic parameter and variable results and conclusions have been reported. Pauwelyn et al. (1988) reported that, Bols (1979) observed that the kinetic energy of storms is high enough to detach sufficient soil and saturate the runoff in sediments. That is the reason, why the impact of overland flow on detachment was neglected. Then, we can say that, soil erosion by water occurs if the combined power of rainfall energy (mechanical detachment) and overland flow energy (hydraulic detachment) exceeds the resistance of soil to detachment. Several researches showed that soil losses were controlled by the erosion index both for natural and simulated rain (Sukhanovskii 2007). Sukhanovskii and Khan (1983) proposed a new approach to evaluate rainfall erosivity based on physical basis. This approach was applied in this study under artificial rainfall intensities.

The aim of this paper is to contribute to finding relationships between the rainfall erosivity index AI generated by the rainfall simulator and the rainfall intensity, the rainfall power, the hydraulics of overland flow, such as depth, velocity, flow regime and sediment concentration using a remolded agricultural sandy soil.

\section{BASIC EQUATIONS}

The rainfall erosivity index AI used in this study is that defined by Sukhanovskii (2007) and recommended by Sukhanovskii and Khan (1983). This index is expressed as:

$$
A I=2.3 \times 10^{4} E c
$$

Where, $E c$ is the kinetic energy of the rain, $\mathrm{J} \cdot \mathrm{m}^{-2}$, given by the following equation:

$$
E c=\frac{1}{2} \rho V I^{2} t
$$


Where, $\rho$ is the water density, $\mathrm{kg} \cdot \mathrm{m}^{-3} ; V$ is the velocity of rain drop, $\mathrm{m} \cdot \mathrm{s}^{-1}$; $I$ is the rainfall intensity, $\mathrm{m} \cdot \mathrm{s}^{-1}$; and $t$ is the time, $\mathrm{s}$.

The rainfall velocity was calculated using the equation (3) reported by Sukhanovskii (2007);

$$
V=\propto_{1} \sqrt{g d[1-\exp (-\beta H / d)]}
$$

Where, $\propto_{1}=\sqrt{4 \rho / 3 \varphi \rho_{\mathrm{a}}}, \beta=3 \varphi \rho_{\mathrm{a}} / 2 \rho, g=9.81 \mathrm{~m} \cdot \mathrm{s}^{-2}$ is gravity acceleration; $d$ is the drop diameter, $\mathrm{m} ; H$ is the height of the drop fall, $\mathrm{m} ; \rho=1,000$ $\mathrm{kg} \cdot \mathrm{m}^{-3}$ is the water density; $\rho_{a}=1.29 \mathrm{~kg} \cdot \mathrm{m}^{-3}$ is the air density; and $\varphi=0.6$ is the dimensionless coefficient of the air resistance. For these given values, $\alpha_{1}=41.5$ and $\beta=1.16 \times 10^{-3}$ (Sukhanovskii 2007).

In this study, the mean diameter of raindrop was determined for each rainfall intensity by using the spots method (blotting paper) (Hudson 1995).

\section{EQUIPMENT AND EXPERIMENTAL PROCEDURE}

\subsection{Rainfall simulator}

To run the experiences, a rainfall simulator (EID 340 ORSTOM) was used, with a spray nozzle fixed at the top of a carriage at a height of about four meters (see detailed: Figure 1). A water pump was used to supply the nozzle with constant discharge. To avoid wetting the surrounding of the simulator, a plastic sheet was fixed round the carriage. To simulate the natural soil, a soil tray was performed according to the width carriage space. The dimensions are $2 \mathrm{~m}$ length, $0.5 \mathrm{~m}$ width and $0.15 \mathrm{~m}$ height. The soil tray was positioned in such a way that, the entire soil surface receives the same rainfall intensity. A sloped collector is fixed at the bottom end of the tray to collect the water/sediments mixture. At the output of the collector, a water tank is put to receive the runoff water. The water tank is empted after each run.

\subsection{Rainfall intensity}

Six simulated rainfall intensities were produced by two spray nozzles of type: TEEJET SS 6560 and $\mathrm{H}^{1 / 4} \mathrm{VV} 8008: 31.40 \mathrm{~mm} \cdot \mathrm{h}^{-1} ; 37.82 \mathrm{~mm} \cdot \mathrm{h}^{-1} ; 69.49$ $\mathrm{mm} \cdot \mathrm{h}^{-1} ; 81.85 \mathrm{~mm} \cdot \mathrm{h}^{-1} ; 90.39 \mathrm{~mm} \cdot \mathrm{h}^{-1}$ and $101.94 \mathrm{~mm} \cdot \mathrm{h}^{-1}$. The nozzles were used separately. The adjustment of these rainfall intensities is performed by varying the pressure using a gate valve at the output of the pump and another gate valve on the bypass line (Figure 1). The swing of the sprinkler is realized by changing the frequency of the battery charger. 
A large number of preliminary tests were performed to obtain the rain intensities with incoming uniformities in the standards. For this, we placed 30 beakers, spread uniformly on the entire surface of the flume soil (Mantovani et al. 1995). The longitudinal distance between two beakers is $6.8 \mathrm{~cm}$ while the transverse distance is $11.3 \mathrm{~cm}$. The volume of water collected in each beaker is measured using a graduated cylinder. This volume is divided by the sampling time and the reception surface of the beaker. The rainfall intensity is the average of five tests run in the same conditions with the same pressure and the same rotation velocity.

Thus the uniformity of the distribution of the rain drops on the soil surface is ensured by evaluating the coefficient of uniformity $\mathrm{CU}$ that must be greater or equal to $80 \%$. According to Mantovani et al. (1995), this coefficient is as follows:

$C u=100 \times\left[\frac{1-\left(\sum_{i=1}^{n}\left|h_{i}-h_{m}\right|\right)}{n \times h_{m}}\right]$

Where, $h_{i}$ is the height of rain in the beaker $\mathrm{i}, \mathrm{mm} ; h_{m}$ is the average heights of rain in the beakers, $\mathrm{mm}$ and $\mathrm{n}$, the number of beakers. Once $\mathrm{CU}$ is justified (greater or equal to $80 \%$ ), the rainfall intensities is selected.

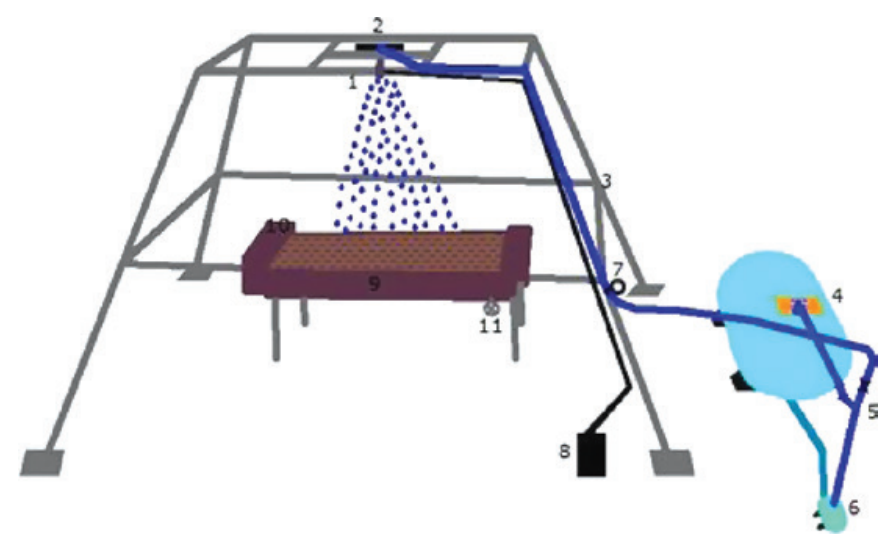

Fig. 1. Scheme of rainfall simulator. 1) Spray nozzle; 2) Sprinkler unit; 3 ) Metallic portico;

4) Tank 600 liters; 5) Valve; 6) Pump; 7) Manometer; 8) Command of the sprinkler unit;

9) Soil tray $2 \times 0.5 \mathrm{~m}^{2} ; 10$ ) Collector of waters; 11) Device of regulation of the flume soil slope

\subsection{Soil preparation and sediment concentration measurement}

The soil used in this study is a remolded agricultural sandy soil collected from the ITCMI Algiers (Technical Institute of Industrial Vegetable Crops), while the physical and chemical analyses of the soil were made in the laboratory of soil science of the INRAA (National Institute of Agronomic Research of Algeria). The results obtained are presented in Table 1. 
Table 1. Characteristics of the used soil

\begin{tabular}{ccccc}
\hline & Gravel & Coarse sand & Sand fine & MO \\
\hline Soil particle fraction $(\%)$ & 20 & 67 & 9 & 4 \\
\hline Dimension $(\mathrm{mm})$ & $2-4$ & $0.2-2$ & $0.05-0.2$ & $/$ \\
\hline
\end{tabular}

First of all, the soil is sieved to remove all the big stone and roots. Then, the soil tray is filled with soil until the surface is flush with the rim of the water collector, using a flat ruler. Before each experience, the soil is saturated using a bucket sprinkler (Pan and Shangguan 2006). This operation is carried out on a horizontal slope.

Once the soil is saturated, we adjust the flume soil at a slope of $3^{\circ}$. This slope is used by several researchers such as (Bryan 1979, Collinet and Valentin 1984).The simulated rainfall is applied as soon as the slope is fixed in the purpose to avoid the heterogeneous of the soil saturation. Once the runoff is established, we collect the volume of water/sediments mixture in a beaker of 1,000 $\mathrm{ml}$, at the output of the collector (see: Figure 1); this operation is reproduced each 4 minutes until the end of the experience (Fox and Bryan 1999). The duration of each collection is 30 seconds. After reading the volume of the mixture collected in the beaker of $1,000 \mathrm{ml}$, we agitate this beaker up and down to have a homogeneous mixture, then we take a volume of $100 \mathrm{ml}$ in a small beaker, which is already weighted. At the end of the experiences, the beakers filled with water/sediments mixture are dried in the oven at $105^{\circ} \mathrm{C}$ for 24 hours until a constant weight (Fox and Bryan 1999, Pan and Shangguan 2006). After 24 hours, we weight the beakers with dry sediments and the difference between the weights of empty and filled beakers gives the mass of sediments in $100 \mathrm{ml}$ (Pan and Shangguan 2006).

\subsection{Hydraulic parameters measurement}

The knowledge on the hydraulic parameters is important in the study of soil erosion. The overland flow results generally from an excess of rainfall intensity compared with the infiltration rate. According to Julien and Simons (1985), the main variables associated with overland flow are: the geometrical variables such as $(\sin \theta)$, which could be replaced by the slope (S), for low values of $(\theta)$ and the length of the slope (L), and the physical variables such as the rainfall intensity (I), the flow depth (h), the mean flow velocity (V), the unit flow discharge $\left(\mathrm{q}_{\mathrm{w}}\right)$, and the roughness coefficient (n). Generally, the parameter associated with sediment discharge $\left(\mathrm{q}_{\mathrm{s}}\right)$ is shear stress of soil surface $(\tau)$. Other properties of overland flow are the acceleration of the gravity, the kinematic viscosity and the density of the flow.

The surface velocity (U) of overland flow is measured by measuring the travel time on 4 positions along the flume soil: $0.5 \mathrm{~m} ; 1.0 \mathrm{~m} ; 1.5 \mathrm{~m}$ and $2.0 \mathrm{~m}$ 
using $\mathrm{KMnO}_{4}$ coloration method. Once the color-front propagation reaches the fixed position, the time is recorded using a stopwatch (Giménez and Govers 2001, Zhang et al. 2003, Pan and Shangguan 2006). This surface velocity measurement is used to evaluate mean flow velocity (V) given by equation (5):

$$
V=2 / 3 U
$$

The surface and mean flow velocity are in $\mathrm{m} \cdot \mathrm{s}^{-1}$. The ratio of $2 / 3$ which could be obtained theoretically, was adapted by Li et al. (1996), and Pan and Shangguan (2006).

Although the flow depth is often a few some millimeters, depending on rainfall intensity, it is still a very important parameter although difficult to measure because of the disturbances generated by the impact of rainfall along the slope length. Several authors measured this depth using a precision ruler (Emmett 1970); others used the equation of continuity (Pan and Shangguan 2006). In our case, the depth is calculated from equation (6):

$$
h=\frac{q_{w}}{V}
$$

Where, $q_{w}$ is unit flow discharge, $\mathrm{m}^{2} \cdot \mathrm{s}^{-1}$ and $V$ is overland flow mean velocity, $\mathrm{m} \cdot \mathrm{s}^{-1}$.

\subsubsection{The flow regime}

Overland flow generated by rainfall is characterized on the one hand, by the Reynolds number, and on the other hand, by the Froude number. The equations (7) and (8) give the values of Reynolds and Froude numbers, respectively:

$$
\begin{aligned}
& R e=\frac{V \times h}{v} \\
& F r=\frac{V}{\sqrt{g \times h}}
\end{aligned}
$$

Where, $V$ is the mean flow velocity, $\mathrm{m} \cdot \mathrm{s}^{-1} ; h$ is the mean flow depth, $\mathrm{m} ; v$ is the kinematic viscosity of water equal to $10^{-6} \mathrm{~m}^{2} \cdot \mathrm{s}^{-1}$; and $g$ is the acceleration of gravity, $9.81 \mathrm{~m} \cdot \mathrm{s}^{-2}$.

\subsubsection{Manning roughness coefficient}

The Manning coefficient (n), which is used to quantify the degree of surface roughness, depends on soil surface characteristics. It can be used to explain the flow retardation. It is calculated by the following equation (Guo et al. 2013b) (9): 


$$
n=\frac{h^{2 / 3} \times S^{0.5}}{V}
$$

Where, the hydraulic radius $R$ is replaced by $h, n$ is in, $\mathrm{s} \cdot \mathrm{m}^{-1 / 3} ; s$ is the surface slope, $V, h$, and $g$ are as defined above.

\subsubsection{Rain power}

During a rainfall event, raindrops hit the soil surface and detach surface particles from the soil matrix. Soil particles detachment depends on rainfall and soil characteristics. Hui-Ming and Chih (2009) reported that the influence of rainfall can be represented by rainfall intensity, ratio of rainfall intensity to flow depth, rainfall velocity, rainfall power, or ratio of rainfall intensity to flow velocity (Ferro et al. 1998). Rainfall power is reported by Gabet and Dunne (2003) and expressed as follows:

$$
P=\frac{\rho I V^{2} \operatorname{Cos} \theta}{2}
$$

Where, $P$ is the rain power, $\mathrm{kg} \cdot \mathrm{s}^{-3} ; \theta$ is the soil surface angle with the horizontal, ${ }^{\circ} ; \rho=1000 \mathrm{~kg} \cdot \mathrm{m}^{-3}$ is the water density; $I$ is the rainfall intensity, $\mathrm{m} \cdot \mathrm{s}^{-1}$; and $V$ is the rainfall velocity, $\mathrm{m} \cdot \mathrm{s}^{-1}$.

\subsubsection{Overland flow power}

Guo et al. (2013b) reported that Lye and Smerdon (1965) are among the earliest who used a hydraulic flume to investigate the relationship between soil erosion and hydraulic shear stress. Later studies by Hairsine and Rose (1992) showed that the shear stress of runoff was not a good predictor for soil detachment, and the stream power of flow (or the unit stream power) was a better one. The stream power $(\omega)$ is the energy of the flow dissipated to the flow boundary layer (Bagnold 1977) and used by many authors.

The stream power $(\omega)$ is reported by Nearing et al. (1997) in the following equation (11).

$$
\omega=\tau V=\rho g h s
$$

Where, $\omega$ is the stream power, $\mathrm{kg} \cdot \mathrm{s}^{-3} ; \tau$ is the hydraulic shear stress, $\mathrm{kg} \cdot \mathrm{m} \cdot \mathrm{s}^{-2}$. 


\section{RESULTS AND DISCUSSION}

\subsection{Rainfall characteristics}

\subsubsection{Mean diameter of rain drops $\left(\mathrm{d}_{50}\right)$}

The curves shown in Figure 2 represent the relationship between the average measured values of rain drop diameter and rainfall intensity of this study compared to the diameter calculated by several authors. The shape of the curve shows that our results are close to those obtained by Sukhanovskii (2007) and Atlas (1953). The relationship between the rain drop diameter, $d$, $\mathrm{mm}$ and the rain intensity $I, \mathrm{~mm} \cdot \mathrm{h}^{-1}$ is best described by a power function with a high coefficient of determination $\mathrm{R}^{2}=0.99$.

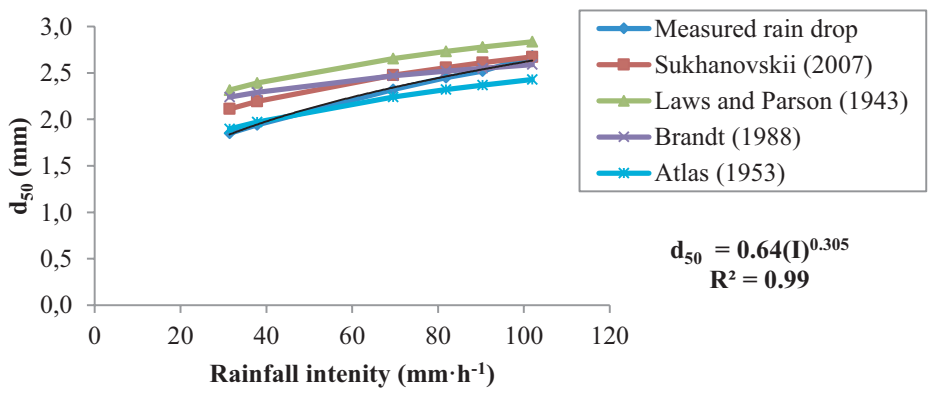

Fig. 2. The relationship between the rainfall intensity and mean rain drop diameter

4.1.2. Relationship between the rainfall erosivity index AI and rain drop diameter

The curve shown in Figure 3 represents the relationship between the measured mean raindrop diameter and the rainfall erosivity index AI. We point out that the relationship evolves in a power function with a high degree of power (6.8) in comparison to the previous relationship between the drop diameter and rainfall intensity with a power degree $(0.31)$. This means that the rainfall erosivity index AI is highly related to drop diameter than rainfall intensity.

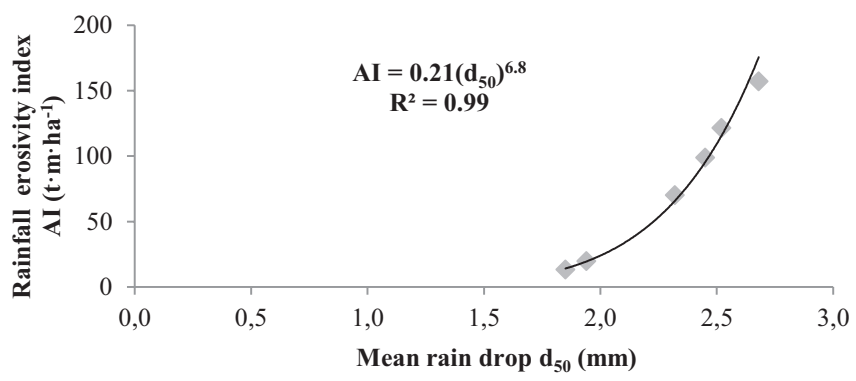

Fig. 3. The relationship between the rain erosivity index and rain drop diameter 


\subsection{Overland flow characterization generated by rainfall intensity}

\subsubsection{Relationship between the rain intensity and flow regime}

The relationships between the rain intensity and the Reynolds and Froude numbers are illustrated in Figures $4 a$ and $4 b$, respectively. The values of the numbers vary with the six rainfall intensities used in this study, between 13 and 38 for the Reynolds number and 0.35 and 0.58 for the Froude number. The values of Reynolds number found in this study are slightly different from those reported by Guy et al. (1990); the authors reported that the Reynolds number is increasing from 36 to 160 with increasing rainfall intensities from $45 \mathrm{~mm} / \mathrm{h}$ to $180 \mathrm{~mm} / \mathrm{h}$. Zhao et al. (2015) found that for a range of rainfall intensities between 30 and $270 \mathrm{~mm} / \mathrm{h}$, the Reynolds number varies between 4 and 122, respectively; then we can say that these findings are almost close to the results reported in this study. For all the rainfall intensities, the corresponding Froude numbers vary between 0.35 and 0.58 ; this means that the overland flow regime is tranquil. Walker et al. (1978) also reported that, for a rainfall intensity of 45 $\mathrm{mm} / \mathrm{h}$, with slope angle of $2.86^{\circ}$, the flow was also tranquil. In a study devoted for sediment transport in rill flow by Polyakov and Nearing (2003), the Reynolds number is between 400 and 1500 and the Froude numbers between 0.25 and 2.1.

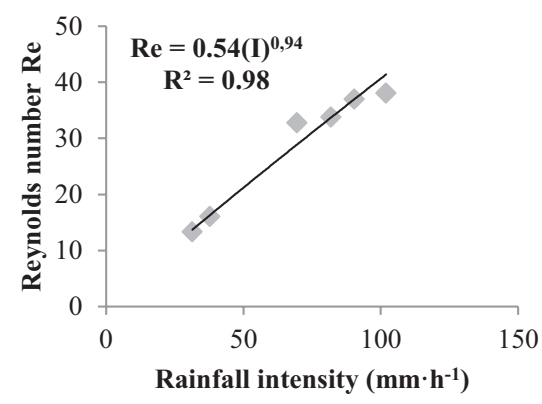

$-a-$

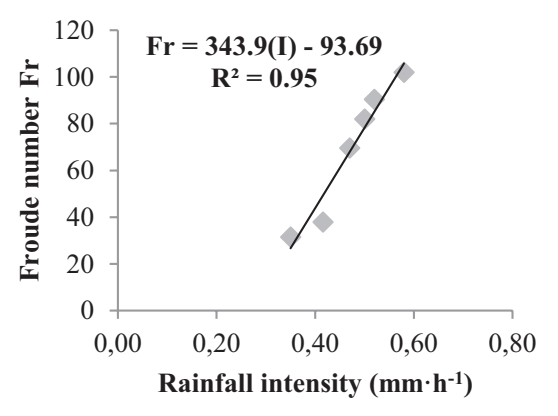

$-b-$

Fig. 4. Overland Flow regime

\subsubsection{Relationship between the rain erosivity index AI and overland flow parameters}

By definition, the rainfall erosivity index AI investigated in this study, is highly related to kinetic energy. The results representing this index AI and the parameters of overland flow such as mean flow velocity, flow depth, the Reynolds and Froude numbers were analyzed statistically and illustrated in Figures $5,6,7$ and 8 . 


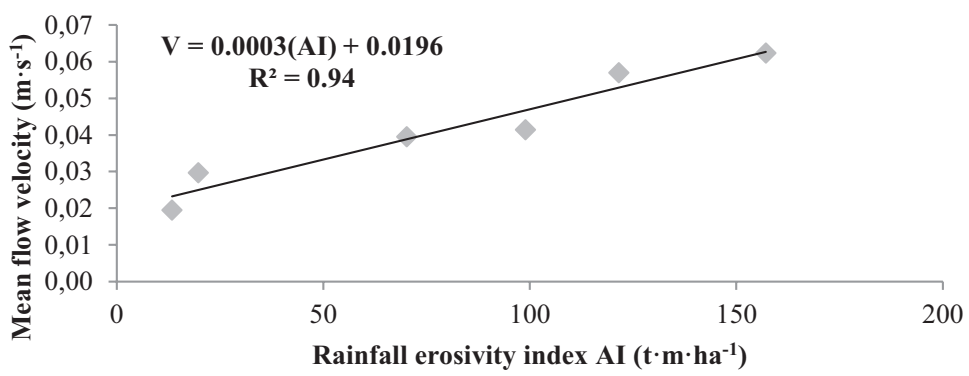

Fig. 5. The relationship between the rainfall erosivity index and mean flow velocity

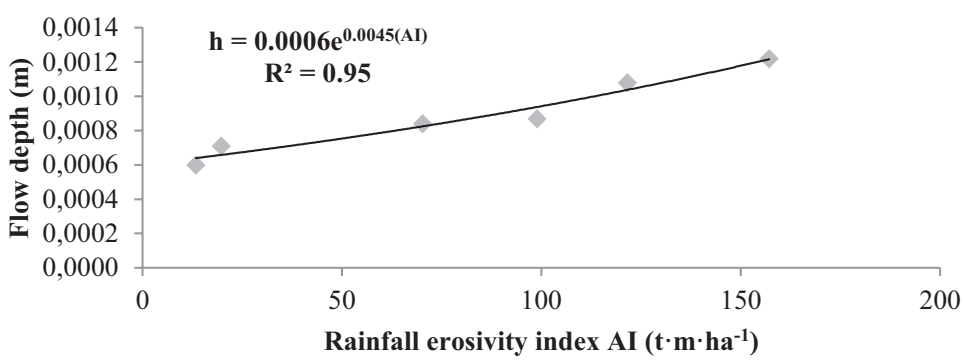

Fig. 6. The relationship between the rainfall erosivity index and flow depth

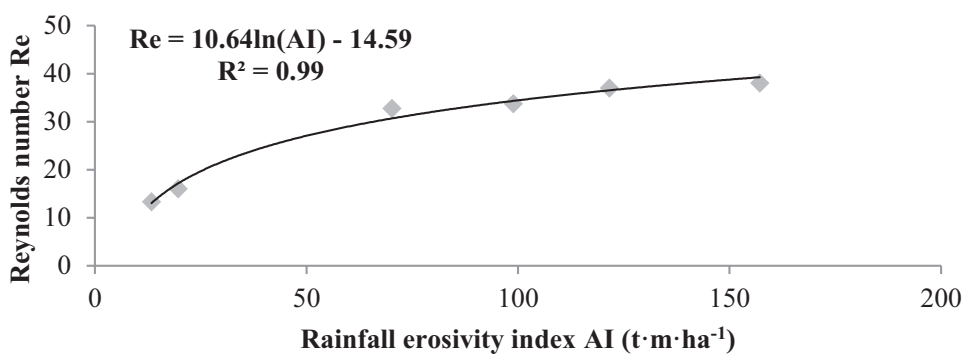

Fig. 7. The relationship between the rainfall erosivity index and Reynolds number

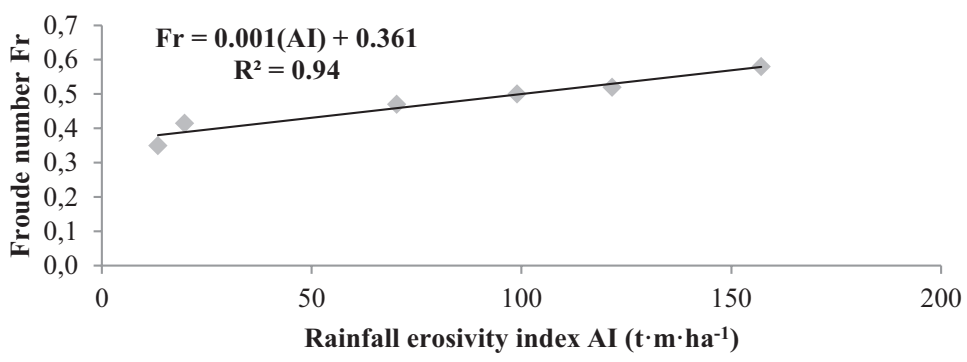

Fig. 8. The relationship between the rainfall erosivity index and Froude number

From the curve in Figure 5, the rainfall erosivity index AI is increasing linearly with increasing the mean flow velocity with high coefficient of determination $\mathrm{R}^{2}=0.94$. The higher the rainfall erosivity index, the greater the mean flow velocity and then more soil particles are loosed. 
As regards the mean flow depth, this parameter is calculated, then it depends on flow velocity and flow discharge. The relationship between this parameter and rainfall erosivity index AI is presented in Figure 6. This relationship is best described by an exponential function with $\mathrm{R}^{2}=0.94$.

Concerning the relationship between overland flow regime and the erosivity index AI, the results are plotted and the curves of the best fit are shown in Figures 7 and 8. From Figure 7, we point out that the relationship between the Reynolds number and AI follows a logarithmic function with $\mathrm{R}^{2}=0.99$. In comparison to the relationship between the Reynolds number and the rainfall intensity, the functions are different with high coefficients of determination. However, the relationship between the Froude number and AI is illustrated in Figure 8 and the curve is following a linear function with significant $\mathrm{R}^{2}=0.94$. In comparison to the previous relationship between Froude number and rainfall intensity, a similar linear regression function is found. From these findings, we can conclude that the Reynolds number reacted differently with rainfall intensity and rainfall index, whereas the Froude number reacted similarly with both parameters.

4.2.3. Relationship between the rainfall erosivity index and the Manning roughness coefficient (n)

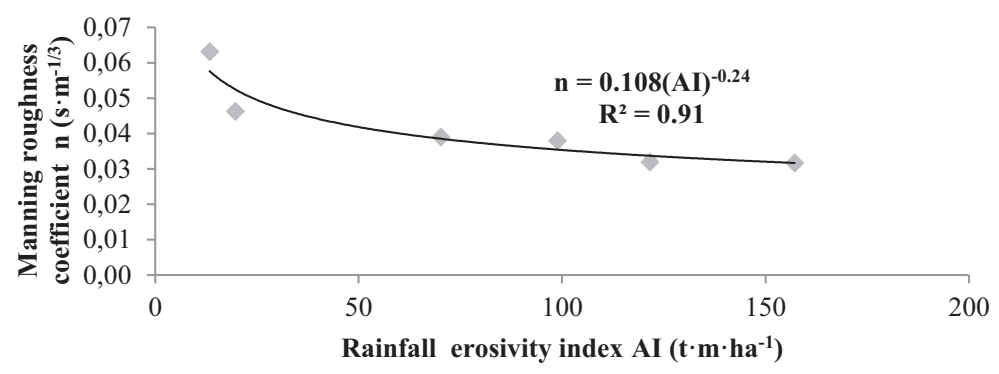

Fig. 9. The relationship between the rainfall erosivity index and Manning roughness coefficient

The Manning roughness (n) is a calculated parameter depending on the flow velocity, on the flow depth and on fixed soil slope in this study. This parameter is related to rainfall erosivity index AI and presented in Figure 9. The regression function relating these parameters is a power function with high coefficient of determination $\mathrm{R}^{2}=0.91$. During the experimental run, some observations have been done. For each rainfall intensity, the roughness decreased with time and at the end of the run, a smooth surface appeared, especially on the end part of the soil tray. 
4.2.4. The relationship between the rainfall erosivity index and the rain power

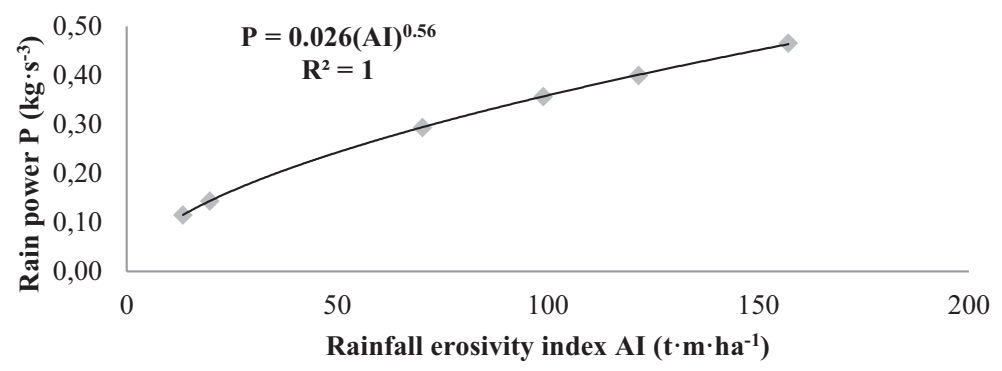

Fig. 10. The relationship between the rainfall erosivity index and rain power

Both parameters are calculated and represent the rainfall impact. The relationship between these two parameters is plotted on Figure 10 and follows a power function with a maximum coefficient of determination $\mathrm{R}^{2}=1$. This coefficient of determination could explain that the rainfall erosivity index AI and the rainfall power have an excellent relationship and express the rain aggressiveness.

4.2.5. The relationship between the rainfall erosivity index and overland flow power

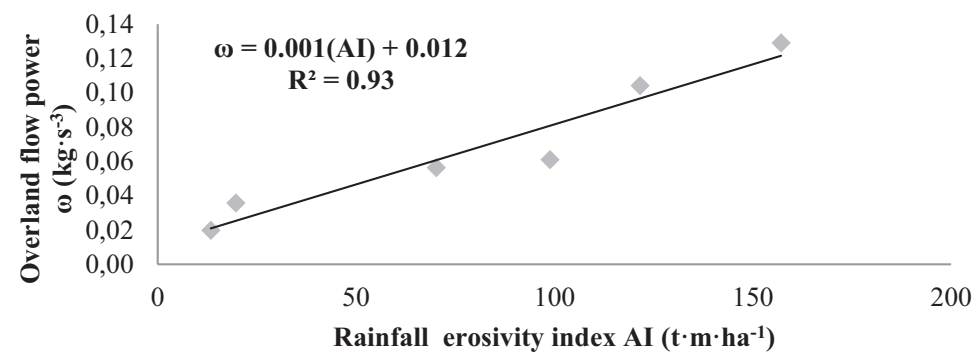

Fig. 11. The relationship between the rainfall erosivity index and overland flow power

The results representing the rainfall erosivity index AI and overland flow power are shown in Figure 11. From the shape of the curve and the statistical analyzes, the linear function with a high coefficient of determination $\mathrm{R}^{2}=0.93$ represents the best fit function. To specify that, overland flow power is a function of overland flow shear stress and mean flow velocity. These both parameters contribute to soil erosion by overland flow; and in the presence of rainfall erosivity index AI, the erosion process is enhanced and more soil particles are detached and loosed. 
4.2.6. The relationship between the rain power and overland flow power

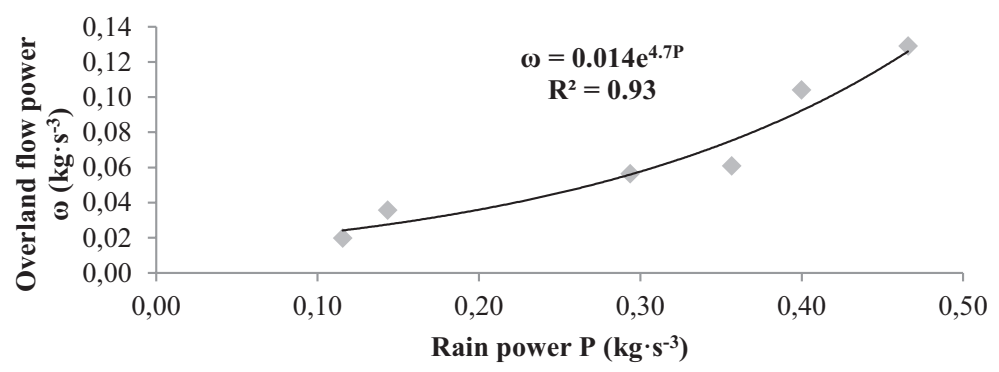

Fig. 12. The relationship between the rain and overland flow power

The relationship between rain power and overland flow power is presented in Figure 12. An exponential function with a high coefficient of determination $\mathrm{R}^{2}=0.93$ is fitted to the curve. As mentioned previously, the rainfall and overland flow together have more power to detach and transport soil particles than each parameter reacted separately. In comparison to the relationship between the rainfall erosivity index AI and overland flow power, we point out that overland flow power reacted differently with $P$ and AI, but with the same coefficient of determination $\mathrm{R}^{2}=0.93$. This could be explained theoretically using equations 1,2 , and 10. In the rain power equation, the slope parameter is present and this could contribute to the effect of rain power on soil erosion, at the same time, in erosivity index equation, the factor time is present and this could contribute to the effect of AI on soil erosion. In addition to this, the powers of both parameters are inversed and this could be one of the reasons to explain the difference between the fitting functions.

\subsection{Rainfall effects on sediment concentration}

4.3.1. Relationship between the rainfall erosivity index and sediment concentration

Sediment concentration against rainfall erosivity index is illustrated in Figure 13. The statistical analysis of the relationship between the rainfall erosivity index, which is a very important factor in the process of detachment of soil particles, and the sediment concentrations, have shown that the relationship is best presented by a power function with a high coefficient of determination of 0.99 . 


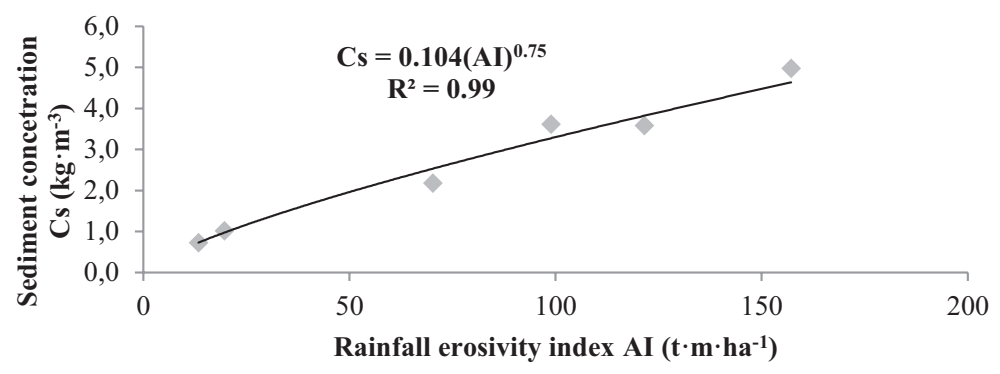

Fig. 13. The relationship between the rainfall erosivity index and sediment concentration

4.3.2. Relationship between the overland flow power and sediment concentration

The relationship between the rate of detachment of soil particles, which is expressed in this study by the values of the concentrations of sediments and the overland flow power, is illustrated in Figure 14. The results of the regression analysis have shown that the relationship follows a power function with a very satisfactory coefficient of determination $R^{2}=0.90$. Whenever Nearing et al. (1997) used six series of experiments to study hydraulics and erosion in eroding rills, they found that the Reynolds number is not a consistent predictor of hydraulic friction, while stream power is a consistent and appropriate predictor for unit sediment load for the entire data set. Their detachment rates are best correlated to a power function of either shear stress or stream power. Zhu et al. (1995) and Zhang et al. (2003) studied the mechanism of soil detachment by shallow flow and found that the linear relationship between detachment rate and shear stress gives a poorer prediction than a power function does, and stream power is a better parameter to predict detachment than shear stress.

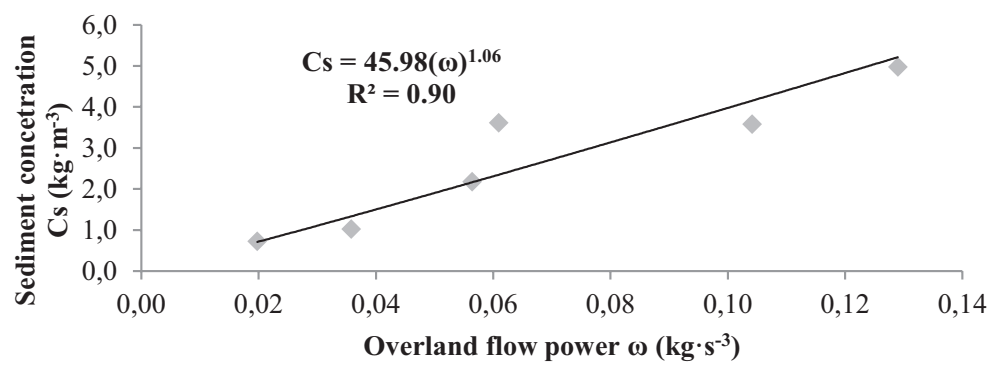

Fig. 14. The relationship between the overland flow power and sediment concentration 


\section{CONCLUSION}

In the light of these results and discussion, we can conclude that the function relating the mean drop diameters and the rainfall intensities follow a power function. In addition to this, the same power function was found between the mean drop diameter and the erosive index AI with a high power, and AI represents better the rainfall then rainfall intensity.

The Reynolds number and the Froude number of overland flow generated by rainfall intensities ranging from $31.4 \mathrm{~mm} \cdot \mathrm{h}^{-1}$ to $101.94 \mathrm{~mm} \cdot \mathrm{h}^{-1}$ were tested and the results have shown a laminar and subcritical regime. In addition to this, the Reynolds number reacted differently with rainfall intensity and rainfall index AI, whereas the Froude number reacted similarly with both parameters.

The erosivity index AI increased linearly with overland flow velocity, whereas, it increased exponentially with depth. The relationships between AI and Reynolds number, Froude number and manning factor follow logarithmic, linear and power functions respectively. In addition to this, overland flow power reacted differently with $\mathrm{P}$ and $\mathrm{AI}$, but with the same coefficient of determination $\mathrm{R}^{2}=0.93$.

The erosivity index is a good indicator of soil erosion and this agreed with the power function found between AI and sediments concentration. The same function was found between sediments concentration and overland flow power, which means it is still the best predictor of soil erosion.

\section{REFERENCES}

[1] Atlas, D., 1953. Optical extinction by rainfall. Journal of Meteorology, 10: 486-488.

[2] Bagnold, R.A., 1977. Bed load transport by natural rivers. Water Resources Research Journal, 13: 303-312.

[3] Bols, P., 1979. Contribution to the study of surface runoff and erosion on Java. Ph.D. study. Faculty of Agriculture. State University of Ghent, Belgium.

[4] Brandt, C.J., 1988. The transformation of rainfall energy by a tropical rain forest canopy in relation to soil erosion. Journal of Biogeography, 15: 41-48.

[5] Bryan, R.B., 1979. The influence of slope angle on soil entrainment by sheetwash and rainsplash. Earth Surface Processes, 4: 43-58.

[6] Collinet, J., Valentin, C., 1984. Evaluation of factors influencing water erosion in West Africa using rainfall simulation. Challenges in African Hydrology and Water Resources. IAHS Publ.144.

[7] El Kateb, H., Zhang, H., Zhang, P., Mosandl, R., 2013. Soil erosion and surface runoff on different vegetation covers and slope gradients: A field experiment in Southern Shaanxi Province, China. Catena 105: 1-10.

[8] Ellison, W.D., 1944. Studies of raindrop erosion. Agricultural Engineering, 25: 131-136, 181-182.

[9] Emmett, W.W., 1970. The hydraulics of overland flow on hillslopes. Geological Survey Professional Paper 662. 
[10] Ferro, V., Porto P., Tusa, G., 1998. Testing a distributed approach for modeling sediment delivery. Hydrological Sciences Journal, 43: 425-442.

[11] Fox, D.M., Bryan, R.B., 1999. The relationship of soil loss by interrill erosion to slope gradient. Catena, 38: 211-222.

[12] Gabet, E.J., Dunne, D., 2003. Sediment detachment by rain power. Water Resources Research, 39: 1-12.

[13] Giménez, R., Govers, G., 2001. Interaction between bed roughness and flow hydraulics in eroding rills. Water Resources Research, 37: 791-799.

[14] Guo, M., Jian, J., Zhao, Z., Jiao, J., 2013a. Measurement on physical parameters of raindrop energy. Springer plus, 2 (Suppl. 1): S16.

[15] Guo, T., Wang, Q., Li, D., Zhuang, J., Wu, L., 2013b. Flow hydraulic characteristic effect on sediment and solute transport on slope erosion. Catena, 107: 145-153.

[16] Guy, B.J., Dickinson, W.T., Rudra, R.P., 1990. Hydraulics of sediment-laden sheet flow and the influence of simulated rainfall. Earth surface Processes and Landforms, 15: 101-118.

[17] Hairsine, P.B., Rose, C.W., 1992. Modeling water erosion due to overland flow using physical principales (Sheet Flow). Water Resources Research, 28: 273-243.

[18] Hudson, N.W., 1995. Soil Conservation (3 ${ }^{\text {rd }}$ ed.), B.T. Batsford, London, p. 391.

[19] Hui-Ming, S., Chih, T.Y., 2009. Estimating overland flow erosion capacity using unit stream power. International Journal of Sediment Research, 24: 46-62.

[20] Julien, P.Y., Simons, D.B., 1985. Sediment transport capacity of overland flow. Transactions of ASAE, 28: 755-762.

[21] Kinnell, P., 1981. Rainfall intensity kinetic-energy relationships for soil loss prediction. Soil Science Society of America Journal, 45 (1): 153-155.

[22] Lal, R., 1977. Analysis of factors affecting rainfall erosivity and soil erodibility. Soil Conservation and Management in the Humid Tropics. John Wiley, Chichester, UK. pp. 49- 56.

[23] Laws, J.O., Parsons, D.A., 1943. The relationship of raindrop size to intensity. Transactions of the American Geophysical Union, 24: 452-460.

[24] Laws, J.O., 1941. Measurements of the fall velocities of waterdrops and raindrops. Transactions of the American Geophysical Union, 22: 709-721.

[25] Li, G., Abrahams, Athol, D., 1996. Correction factors in the determination of mean velocity of overland flow. Earth Surface Processes and Landforms, 21: 509-515.

[26] Mantovani, E.C., Villalobos, F.J., Organ, F., Fereres, E., 1995. Modelling the effects of sprinkler irrigation uniformity on crop yield. Agricultural Water Management, 27: 243-257.

[27] Marshall, J.S., Palmer, W.M., 1948. The distribution of raindrops with size. Journal of Meteorology. 5: 165-166.

[28] Meyer, L.D., 1958. An investigation of methods for simulating rainfall on standard run-off plots and a study of the drop size, velocity, and kinetic energy of selected spray nozzle. Purdue University. Special Report, 81, p.42.

[29] Mualem, Y., Assouline, S., 1986. Mathematical model for rain drop distribution and rainfall kinetic energy. Transactions of ASAE, 29(2): 494-500.

[30] Nearing, M.A., Norton, L.D., Bulkakov, D.A., Larionov, G.A., West L.T., Dontsova, K.M., 1997. Hydraulics and erosion in eroding rill. Water Resources Research, 33: 865-876.

[31] Palmer, R.S., 1965. Waterdrop impact forces. Transactions of ASAE, 8(1): 69-72.

[32] Pan, C., Shangguan, Z., 2006. Runoff hydraulic characteristics and sediment generation in sloped grassplots under simulated rainfall conditions. Journal of Hydrology, 331: 178-185.

[33] Pauwelyn, P.L.L., Lenvain, G.J.S., Sakala, W.K., 1988. Iso-erodent map of Zambia. Part I: the calculation of erosivity indices from a rainfall data bank. Soil technology, 1: 235-250.

[34] Polyakov, V. O., Nearing, M. A., 2003. Sediment transport in rill flow under deposition and detachment conditions, Catena, 51: 33-43.

[35] Sukhanovskii, Yu., P., 2007. Modification of a rainfall simulation procedure at runoff plots for soil erosion investigation. Eurasian Soil Science, 2: 195-202. 
[36] Sukhanovskii, Yu., P., Khan, K., Yu., 1983. Erosion characterization of rain. Pochvovedenie, 9: $123-125$.

[37] Walker, P.H., Kinnell, P., Green, P., 1978. Transport of a noncohesive sandy mixture in rainfall and runoff experiments. Soil Science Society of America Journal, 42: 793-801.

[38] Wischmeier, W.H., 1959. A Rainfall erosion index for a universal soil loss equation. Soil Science Society of America Journal, 23: 246-249.

[39] Wischmeier, W.H., Smith, D.D., 1978. Predicting rainfall erosion losses. Agricultural Handbook No.537. Washington, D C.

[40] Zachar, D., 1982. Soil Erosion. Developments in soil science 10. Forest Research Institute, Zvolen, Czechoslovakia, p. 548.

[41] Zhang, G.H., Liu, B.Y., Liu, G.B., He, X.W., Nearing, M.A., 2003. Detachment of undisturbed soil by shallow flow. Soil Science Society of America Journal, 67: 713-719.

[42] Zhao, Q., Li, D., Zhuo, M., Guo, T., Liao, Y., Xie, Z., 2015. Effects of rainfall intensity and slope gradient on erosion characteristics of the red soil slope. Stochastic Environmental Research Risk Assessment, 29: 609-621.

[43] Zhu, J.C., Gantzer, C.J., Anderson, S.H., Peyton, R.L., Alberts, E.E., 1995. Simulated small channel bed scour and head cut erosion rates compared. Soil Science Society of America Journal, 59: 211-218. 